\title{
An in vitro comparative Evaluation of Fracture Strength of Roots Instrumentated with Self-adjusting File and Reciproc Reciprocating File, with and without Obturation
}

\author{
${ }^{1}$ Sakshi Tyagi, ${ }^{2}$ Ekta Choudhary, ${ }^{3}$ Pooja Kabra, ${ }^{4}$ Rajat Chauhan
}

\begin{abstract}
Aim: The purpose of this study was to evaluate the fracture strength of roots instrumented with the self-adjusting file (SAF; ReDent-Nova, Ra'anana, Israel) and the Reciproc reciprocating file and that were and were not obturated using the warm vertical lateral compaction technique.

Materials and methods: In total, 75 mandibular premolar teeth were sectioned at or below the cementoenamel junction to obtain roots $13 \mathrm{~mm}$ in length. The roots were balanced with respect to buccolingual and mesiodistal diameters and weight. They were distributed into four experimental groups and one control group $(n=15)$ : No instrumentation (group I), instrumentation with SAF files but no obturation (group II), instrumentation with SAF files and obturated with warm vertical lateral compaction (group III), instrumentation with Reciproc File but no obturation (group IV), and instrumentation with Reciproc File and obturated with warm vertical lateral compaction (group V). AH Plus sealer (Dentsply DeTrey, Konstanz, Germany) was used along with gutta-percha points. One week later, a vertical load was applied to the specimen's canal until fracture occurred. Data were statistically analyzed using one-way analysis of variance $(p=0.05)$.
\end{abstract}

Results: The mean fracture load was $312.83 \mathrm{~N}$ for group I, $297.35 \mathrm{~N}$ for group II, $359.15 \mathrm{~N}$ for group III, $231.51 \mathrm{~N}$ for group IV, and $275.81 \mathrm{~N}$ for group $\mathrm{V}$.

Conclusion: The fracture resistances exhibited a statistically significant difference between all the groups. Teeth instrumented by SAF exhibited a better fracture resistance.

Keywords: Fracture strength, Instrumentation, Reciproc reciprocating file, Root fracture, Self-adjusting file.

How to cite this article: Tyagi S, Choudhary E, Kabra P, Chauhan R. An in vitro comparative Evaluation of Fracture Strength of Roots Instrumentated with Self-adjusting File and Reciproc Reciprocating File, with and without Obturation. Int J Clin Dent Res 2017;1(1):20-25.

Source of support: Nil

Conflict of interest: None

\footnotetext{
${ }^{1,4}$ Postgraduate Student, ${ }^{2}$ Professor and Head, ${ }^{3}$ Reader

${ }^{1-3}$ Department of Conservative Dentistry and Endodontics School of Dental Sciences, Greater Noida, Uttar Pradesh, India

${ }^{4}$ Department of Orthodontics and Dentofacial Orthopedics School of Dental Sciences, Greater Noida, Uttar Pradesh, India

Corresponding Author: Sakshi Tyagi, 59, Ansal Garden Enclave, Hapur Road, Ghaziabad, Uttar Pradesh, India, e-mail: drsakshi5tyagi@gmail.com
}

\section{INTRODUCTION}

Root canal system instrumentation is an essential aspect of endodontic therapy, which aims to thoroughly debride, while maintaining the original shape of the root canal without harming dentin integrity. ${ }^{1}$

Vertical root fracture (VRF) is a challenging complication that may occur during or after root canal treatment procedures. In root canal preparation, dentin is removed, which compromises the fracture strength of the roots. One of the important causes of endodontic failure is VRF. The predisposing factors contributing for VRFs include the loss of tissue, dehydration of dentin, effects of irrigation solutions, and use of excessive pressure during root-filling procedures.

Over the last few decades, endodontic instrumentation has evolved on the line of technological advancements. The currently used motorized file systems consist of a solid metal core, with rotating blades and flutes. These files are designed with increasing taper, resulting in active cutting, and relative removal of more dentin. In addition, excessive taper results in more removal of dentin reducing the fracture strength. From a fracture mechanics point of view, the presence of structural defects, cracks, or canal irregularities is likely to play a major role in determining fracture strength because an applied stress may be exponentially amplified at the tip of those defects.

Recently introduced self-adjusting file (SAF) (ReDentNova, Ra'anana, Israel) is designed as a hollow and flexible file that adapts itself to the root canal shape. It addresses higher percentages of the irregularly shaped root canals than the rotary/reciprocating files, providing a cleaner radicular dentin surface for successful threedimensional obturation. ${ }^{2}$ Owing to abrasive surface, SAF abrades the dentin from the entire perimeter of the canal maintaining dentin integrity. The SAF is a system of root canal-shaping irrigation that in the emerging literature is proving to be minimally invasive. In comparison to rotary files, it is shown to respect the root canal integrity in a much more superior way.

Reciproc reciprocating file is currently one of the leading reciprocating systems available with $\mathrm{M}$ wire technology and advantages of reciprocation. It has shown to have a higher resistance to cyclic fatigue. Reciproc is 
a single file system with a canal preparation time of onefourth of the time taken by contemporary nickel-titanium (NiTi) rotary files.

Another element directly related to the fracture resistance is the creation of microcracks in radicular dentin. All the currently used rotary and reciprocating files create microcracks ranging from 18 to $60 \%$ in the roots instrumented. Various studies have been reported on the fracture resistance of teeth and formation of microcracks in the radicular dentin. Till now, there are only few reports on comparing fracture resistance of teeth instrumented by Reciproc reciprocating file system and SAFs. Hence, the purpose of this study was to assess and compare the fracture resistance of the teeth after the instrumentation by SAF and Reciproc Files that were and were not obturated using the warm vertical lateral compaction technique.

\section{MATERIALS AND METHODS}

A total of 75 extracted human mandibular premolars with single root canals were selected and stored in $10 \%$ buffered formalin. The teeth were examined with a stereomicroscope under $10 \times$ magnification to detect craze lines or cracks. The coronal portions of all teeth were removed by using a diamond-coated disk under water cooling, leaving roots approximately $13 \mathrm{~mm}$ in length. All the roots were measured with respect to buccolingual (BL) and mesiodistal (MD) diameters using vernier caliper. The roots were weighed with high-sensitive precision analytical balance (WENSAR). This parameter were assessed by using the analysis of variance test $(p=0.457$ for the weights and $p=0.989$ for the products of the BL and MD diameter.)

The roots were distributed into four experimental groups and one control group $(n=15)$

\section{Group I Control: No Instrumentation or Obturation}

The root canals were not shaped or obturated.

\section{Group II: Instrumentation with SAF without Obturation}

The root canals were prepared first with 20/0.04 rotary file for glide path. The SAF system was used with an in-andout vibrating hand piece combined with an RDT3 head (ReDent Nova, Ra'nana, Israel) at a frequency of 5,000 movements / minute with an amplitude of $0.4 \mathrm{~mm}$. Irrigation with $2.5 \% \mathrm{NaOCl}$ was applied through the hollow file throughout the 4 minutes of operation. The irrigant was continuously provided by a VATEA peristaltic pump (ReDent Nova), which comes with the SAF system at a rate of $4 \mathrm{~mL} /$ minute. After instrumentation, a final flush was applied using $5 \mathrm{~mL} \mathrm{17 \%}$ ethylenediaminetetraacetic acid for 15 seconds and $5 \mathrm{~mL} 2.5 \% \mathrm{NaOCl}$ for 1 minute, followed by the final rinse with $5 \mathrm{~mL}$ distilled water.

\section{Group III: Instrumentation with SAF using Warm Vertical Compaction Technique}

The root canals were instrumented and irrigated in the same way as those in group II. An individual gutta-percha master cone \#40 with 0.06 taper (Dentsply-Maillefer, Ballaigues, Switzerland) coated with AH-Plus sealer was fit with tug back in each root canal and obturated with warm vertical compaction technique. The excess material was removed and condensed with a cold plugger for 5 seconds at $1 \mathrm{~mm}$ below the canal orifice.

\section{Group IV: Instrumentation with Reciproc Rotary Files without Obturation}

A size 20 hand file was inserted passively to the working length and then a R25 Reciproc file having a size 25 at the tip and a taper of 0.08 over the first $3 \mathrm{~mm}$ were used in a reciprocating, slow in-and-out motion according to the manufacturer's instructions. The flutes of the instrument were cleaned after three in-and-out movements (pecks). The irrigation protocols were the same as for the standard preparation technique.

\section{Group V: Instrumentation with Reciproc Rotary Files using Warm Vertical Compaction Technique}

The root canals were instrumented and irrigated in the same way as those in group IV. An individual Reciproc filling gutta-percha master cone R25 coated with AH-Plus sealer was fit with tug back in each root canal and obturated with warm vertical compaction technique. The excess material was removed and condensed with a cold plugger for 5 seconds at $1 \mathrm{~mm}$ below the canal orifice.

The roots of all five groups were kept at $37^{\circ} \mathrm{C}$ with $100 \%$ humidity for 7 days to allow the sealer to set.

\section{TESTING FRACTURE STRENGTH OF SAMPLES}

Self-cured acrylic resin was used to prepare acrylic resin block using cylindrical metal molds $(25 \mathrm{~mm}$ high and $10 \mathrm{~mm}$ in diameter). The apical root ends were embedded vertically in $4 \mathrm{~mm}$ of the acrylic resin, exposing $9 \mathrm{~mm}$ of the coronal portion of each root. The roots were hydrated with a wet towel until they were ready for strength testing.

An instron testing machine running at a cross-head speed of $1 \mathrm{~mm} /$ minute was used to fracture the roots. A steel conical tip (diameter $=0.5 \mathrm{~mm}$, tapered at $60^{\circ}$ ) was mounted and aligned with the center of the canal orifice 
parallel to the long axis of each specimen, and the load necessary to fracture was expressed in Newton. Data obtained were subjected to statistical analysis to attain the final results.

\section{STATISTICAL EVALUATION}

The variable fracture load was continuous and thus summarized as mean and standard deviation. The values obtained were checked for normality; statistical analysis was performed by Shapiro Wilk test. Keeping in view the nature (continuous) and distribution (normal) of data, inferential statistics were performed using parametric tests of significance.

Inferential statistics were performed using one-way analysis of variance test. One-way analysis of variance test was used for intergroup comparison of fracture load. Post hoc pairwise comparison was done using post hoc Tukey's test. For all the statistical tests, "p" was less 0.05 was taken to indicate significant difference.

\section{RESULTS}

The fracture loads of the roots and other variables in the five groups are shown in Table 1. Statistical analysis confirmed the standardization of roots among groups with respect to weight, BL and MD diameter, and multiplication of the BL-MD diameter. The intergroup comparison of BL diameter of canals showed that there was a statistically significant difference in the BL diameter of canals of specimens among five groups. The BL diameter of group II specimens was found to be significantly higher than that among specimens in other groups. The intergroup comparison of MD diameter of canals showed no statistically significant difference in the MD diameter of canals of specimens among the five groups.

The comparison showed no statistically significant difference in the product of MD and BL diameter of canals of specimens among five groups. The weights of the roots were tested statistically, and no significant differences were found between groups.

All of the roots were fractured vertically in the labiolingual direction during testing.

The intergroup comparison of fracture load of canals showed that there was a statistically significant difference in the fracture load of specimens among five groups.
The fracture load of group III specimens was found to be significantly higher than that of all the other groups. It was followed by groups I, II, V, and IV in decreasing order. Although fracture load of group I was more than that of group II, this difference failed to reach the level of statistical significance. Similarly, fracture load of groups II and V also did not show any significant difference, but fracture load of group I was significantly higher than that of group V. Fracture loads of group IV specimens were significantly lower than that of all the other groups.

In the present study, it was found that group III showed the highest fracture load $(359.15 \mathrm{~N})$ and group IV showed the least fracture load $(231.51 \mathrm{~N})$.

\section{DISCUSSION}

The strength of endodontically treated teeth is affected by several predisposing factors, such as excessive loss of tooth structure due to caries or trauma, dehydration of dentin, access cavity preparation and biomechanical preparation, undesirable effects of irrigation solutions, excessive pressure during filling procedures, and preparation of intraradicular post space. Experimental studies have shown that excessive removal of dentin during root canal preparation, post space preparation, and obturation procedures increases susceptibility to root fracture. Clinically, these fractures may decrease the long-term survival rate. During shaping, geometric design of various rotary instruments also affects the root stresses.

Reddy et $\mathrm{al}^{3}$ determined fracture resistance of tooth roots after different instrumentation techniques and concluded that conventional hand instrumentation technique showed highest fracture resistance with least amount of dentin removed. In another study, authors found that hand instrument has more resistance when compared with a rotary instrument. ${ }^{4}$

Over the last decades, technological advances in endodontic treatment with rotary instruments have led to new design concepts. ${ }^{5}$ Various studies concluded that rotary instruments exhibit higher performance than hand instruments, such as easier, faster, and better root canal shaping and less apical canal transportation. ${ }^{6-8}$ Recently, manufacturers have introduced a new generation of rotary instruments with a variable cross-sectional design and different working motions, which complete canal preparation with only one instrument.

Table 1: Cross-sectional diameters, multiplication of the BL-MD diameters, weights, and fracture loads of the roots

\begin{tabular}{lllllll}
\hline Groups & $n$ & $B L$ & $M D$ & Multiplication of BL and MD & Weight & Fracture load $(n)$ \\
\hline I & 15 & $7.22 \pm 0.05$ & $5.05 \pm 0.27$ & $36.48 \pm 2.01$ & $0.42 \pm 0.03$ & $312.83 \pm 24.05$ \\
II & 15 & $7.35 \pm 0.16$ & $4.94 \pm 0.36$ & $36.25 \pm 2.75$ & $0.41 \pm 0.03$ & $297.35 \pm 21.10$ \\
III & 15 & $7.23 \pm 0.11$ & $5.10 \pm 0.03$ & $36.92 \pm 0.65$ & $0.41 \pm 0.03$ & $359.15 \pm 35.78$ \\
IV & 15 & $7.21 \pm 0.07$ & $5.12 \pm 0.05$ & $36.94 \pm 0.58$ & $0.41 \pm 0.03$ & $231.51 \pm 8.96$ \\
V & 15 & $7.19 \pm 0.08$ & $5.07 \pm 0.22$ & $36.48 \pm 1.76$ & $0.41 \pm 0.03$ & $275.81 \pm 12.42$ \\
\hline
\end{tabular}


Single file techniques used for root canal preparation are mostly based on practicability, simplicity, and lower stress values on root canal walls than others. ${ }^{9,10}$ To the best of our knowledge, there are few literature on comparative analysis of SAFs and Reciproc rotary files systems regarding fracture strength. The present study was, therefore, taken to evaluate and compare the effect of SAF and Reciproc reciprocating file on the fracture strength of roots, with and without obturation.

Standardization of the samples is an important factor in mechanical testing. Dimensional variations of the roots, extraction time, and storing conditions might affect the results of a study. ${ }^{11}$ It would be difficult to show statistically significant differences with this wide range of randomly collected extracted teeth. ${ }^{12}$

In some studies, BL and MD diameters were measured, but the weights of the roots were not measured. ${ }^{11,13-15}$ In this study, as similar teeth as possible were selected, and the diameter and the weight of the root were measured where BL diameter showed statistically significant difference, MD diameter and weight showed no statistically significant difference among all five groups, but the change found in BL diameter did not make any difference in standardization of the tooth. This can be attributed to a similar study conducted, which concluded that the volume and weight of the roots had a more significant effect than BL and MD dimensions. ${ }^{16}$ This implies that volume or weight had greater importance regarding the prediction of fracture strength. Authors resulted that the properties with higher correlation coefficient mean higher effect on root strength, ${ }^{16}$ but the results of the present study showed that the weights of the roots had a medium correlation with fracture loading. However, multiplication of the BL and MD diameter had a low correlation with fracture loading as the standardization of the samples was done before mechanical testing to ensure homogeneity in the results.

Wu et a ${ }^{17}$ conducted a study to compare mandibular premolars and canines with respect to their resistance to VRF, and they concluded that instrumented mandibular premolars have a higher risk to fracture than the uninstrumented mandibular premolar, which comes in favor of present study where group I showed higher fracture resistance than groups II, IV, and V.

Root canal instrumentation using the rotary and reciprocating files reduces the fracture resistance of the instrumented tooth up to $30 \%{ }^{17}$

Kim et $\mathrm{al}^{18}$ reported that the rotary files generate a stress of 311 to $368 \mathrm{MPa}$ on the outer surface of the dentin. The tensile strength of the radicular dentin is $106 \mathrm{MPa}$. The stress generated by such files is three times larger than the strength of the dentin, resulting in microcracks. These files possess a solid metal core with flutes and blades for increased cutting. Also, the large-sized taper of these files results in excessive, unnecessary removal of the dentin, thus weakening the root, and such aggressive cutting of the dentin may contribute to microcrack formation.

In a study, the authors concluded that file design affected apical stress and strain concentrations during instrumentation, which were linked to an increase in dentinal defects and canal deviations. These, in turn, were associated with increased VRF susceptibility because root canal obturation and final restoration can initiate or propagate cracks from such defects. ${ }^{19}$

Reciprocating files create a larger number of microcracks, ${ }^{18,20}$ which may be the reason for the reduced fracture resistance exerted by the teeth in groups IV and $\mathrm{V}$ in the current study.

Reciprocating files are characterized by a triangular or modified triangular cross-section, resulting in a low cutting efficiency and less chip space. An increased cutting ability is usually associated with an improved cleaning efficacy, and the reciprocal motion seems to enhance debris transportation toward the apex and may result in increased torsional forces. ${ }^{21}$

The study done by Bürklein et $\mathrm{al}^{20}$ was in agreement with the present study; they reported that this newer generation reciprocating instrument, Reciproc reciprocating files, caused significantly more microcracks than a full sequence of rotary files, which may be the cause of less fracture resistance exhibited by the teeth in groups IV and $\mathrm{V}$ instrumented by Reciproc files in the present study.

The discrepancy between the apical size of rotary/ reciprocating files and the actual cross-section of the apical part of canals led to the recommendation to use larger files for apical preparations in order to address the entire perimeter of the canal wall. This often results in the excessive removal of dentin in the apical third reducing the strength. ${ }^{20}$

The SAF is a hollow file composed of NiTi lattice. It is devoid of any metal core or flutes and blades; it does not cut the dentin. Instead, it has an abrasive surface that abrades the dentin, restricting the removal of the intact dentin. ${ }^{2,22,23}$ It has been reported in the literature that the instrumentation of the root canals using the SAF system resulted in least dentinal microcrack formation. ${ }^{24,25}$ Similar results were found supporting the existing literature that the root canal instrumentation with the SAF with obturation exhibited a higher resistance to fracture when compared with the other groups.

Yoldas et $\mathrm{al}^{24}$ and Liu et $\mathrm{al}^{26}$ conducted a study that was in favor of the present study. They found that the samples instrumented with SAF and hand files exhibited no microcracks in the radicular dentin. 
The less stress generation and no microcracks formed in the radicular dentin could be attributed to the higher fracture resistance of the teeth instrumented by the SAF in the study reported by Pawar et $\mathrm{al}_{,}{ }^{27}$ which also favors the present result.

Kim et $\mathrm{al}^{28}$ reported that the stress generated by the SAF was approximately $10 \mathrm{MPa}$, which could be attributed to the very few-to-no microcracks created using SAF, thus increasing the fracture resistance of the treated teeth.

The result of this study and other previous studies that were in favor of the present study showed the fracture resistance of teeth comparing teeth instrumented with SAF and ProTaper rotary files obturated with guttapercha and $\mathrm{AH}$ Plus sealer and found that the SAFs exhibit highest fracture resistance. ${ }^{29}$

The root canal sealers when used result in filling the gaps between gutta-percha cones and the walls of the radicular dentin. ${ }^{30}$ It had been reported in previous studies that epoxy resin-based sealers have higher adhesion to root canal dentin and deeper penetration into dentinal tubules, resulting in higher retention of the filling material by mechanical locking between the canal walls and the sealers. ${ }^{31,32}$ Hence, a combination of gutta-percha and AH Plus sealer was used in the present study to improve the fracture strength of an endodontically treated tooth.

In the present study, obturation of the root canals with an epoxy resin-based sealer, AH Plus, significantly strengthens the roots compared with the instrumented, but not obturated ones. These results corroborate those of a previous study in which authors concluded that AH plus showed better fracture resistance among the sealer groups where they compared the effect of two resin sealers and a mineral trioxide aggregate sealer on the fracture resistance of endodontically treated teeth. ${ }^{33}$

Chadha et $\mathrm{al}^{34}$ also compared a study to evaluate the effect of various obturating materials on fracture resistance of root canal-treated teeth, where the authors found that teeth obturated with AH Plus + gutta-percha are more resistant to fracture than those obturated with Resilon-Epiphany, zinc oxide-eugenol, and unobturated group.

The use of incubator in which the roots were placed at $37^{\circ} \mathrm{C}$ with $100 \%$ humidity for 7 days was to allow the sealer to set before strength testing in the study to facilitate sealer to set completely.

Bone support and the periodontal ligament are important for the mechanisms of stress distribution over teeth. The root embedment material should reproduce bone capacity to absorb masticatory load and thus support the compressive and tangential force in a fracture resistance test.For this reason, acrylic resin was used to embed the samples. ${ }^{35}$
For the present study, before mechanical testing, each root was embedded vertically in an acrylic resin block leaving its coronal $9 \mathrm{~mm}$ exposed. This design is more relevant clinically, as it efficiently simulates the support given to healthy teeth by alveolar bone and results in less catastrophic stress buildups caused by unrealistic bending movements. ${ }^{36}$

Fracture strength is commonly evaluated to assess the weakening of the root after different procedures, and it involves application of an external force until the root fractures. Several studies showed that instrumentation of the root canals induces craze lines and incomplete cracks, whereas the SAF has a tendency to cause less dentinal cracks when compared with other rotary NiTi files. ${ }^{24-26}$ When an external force is applied, the craze lines and incomplete cracks in the dentin may become high-stress concentration areas from which the crack may gradually propagate to the root canal surface. ${ }^{37}$ Vertical root fractures are the end results of the propagation of a crack. ${ }^{19}$

The results of the present study indicate that the instrumentation decreases the fracture resistance of teeth by either SAF or reciprocating files. The samples instrumented using the SAF exhibited better fracture resistance when compared with the other experimental groups.

\section{CONCLUSION}

Within the limitation and standardization conditions of this study, it can be concluded that the samples instrumented by the SAF exhibited a better fracture resistance when compared with Reciproc reciprocating file systems when not obturated or when obturated with gutta-percha and epoxy-based sealer. Further studies are required with long-term trials with varying parameters simulating the clinical conditions.

\section{REFERENCES}

1. Fuss Z, Lustig J, Tamse A. Prevalence of vertical root fractures in extracted endodontically treated teeth. Int Endod J 1999 Aug;32(4):283-286.

2. Metzger Z, Teperovich E, Zary R, Cohen R, Hof R. The self-adjusting file (SAF). Part 1: Respecting the root canal anatomy - a new concept of endodontic files and its implementation. J Endod 2010 Apr;36(4):679-690.

3. Reddy MS, Reddy PV, Reddy TJ, Balagopal S, Amalavathy K, Reddy GJ, Harini T, Reddy SS. An in vitro study to determine fracture resistance of tooth roots after different instrumentation techniques. J Dr NTR Univ Health Sci 2016 Jul;5(3): 192-199.

4. Saeed MH, Zeinabbardestani, El Sadek DA, Ismail AI. Influence of hands stainless steel and -Ni-Ti rotary file on the resistance to fracture of endodontic treated roots. Int J Recent Sci Res 2014 Mar;5(3):660-664.

5. Gianluca G. The K3 rotary Nickel titanium instrument system. Endod Topics 2005 Mar;10(1):179-182. 
6. Guelzow A, Stamm O, Martus P, Kielbassa AM. Comparative study of six rotary nickel-titanium systems and hand instrumentation for root canal preparation. Int Endod J 2005 Oct;38(10):743-752.

7. Ankrum MT, Hartwell GR, Truitt JE. K3 Endo, ProTaper, and ProFile systems: breakage and distortion in severely curved roots of molars. J Endod 2004 Apr;30(4):234-237.

8. Park H. A comparison of Greater Taper files, ProFiles, and stainless steel files to shape curved root canals. Oral Surg Oral Med Oral Pathol Oral Radiol Endod 2001 Jun;91(6):715-718.

9. Capar ID, Ertas H, Ok E, Arslan H. Comparison of single cone obturation performance of different novel nickel-titanium rotary systems. Acta Odontol Scand 2014 Oct;72(7):537-542.

10. Bier CA, Shemesh H, Tanomaru-Filho M, Wesselink PR, Wu MK. The ability of different nickel-titanium rotary instruments to induce dentinal damage during canal preparation. J Endod 2009 Feb;35(2):236-238.

11. Cobankara FK, Ungör M, Belli S. The effect of two different root canal sealers and smear layer on resistance to root fracture. J Endod 2002 Aug;28(8):606-609.

12. Sathorn C, Palamara JE, Messer HH. A comparison of the effects of two canal preparation techniques on root fracture susceptibility and fracture pattern. J Endod 2005 Apr;31(4):283-287.

13. Trope M, Ray HL Jr. Resistance to fracture of endodontically treated roots. Oral Surg Oral Med Oral Pathol 1992 Jan;73(1):99-102.

14. Zandbiglari T, Davids H, Schäfer E. Influence of instrument taper on the resistance to fracture of endodontically treated roots. Oral Surg Oral Med Oral Pathol Oral Radiol Endod 2006 Jan;101(1):126-131.

15. Johnson ME, Stewart GP, Nielsen CJ, Hatton JF. Evaluation of root reinforcement of endodontically treated teeth. Oral Surg Oral Med Oral Pathol Oral Radiol Endod 2000 Sep;90(3):360-364.

16. Ertas H, Sagsen B, Arslan H, Er O, Ertas ET. Effects of physical and morphological properties of roots on fracture resistance. Eur J Dent 2014 Apr-Jun;8(2):261-264.

17. Wu MK, van der Sluis LW, Wesselink PR. Comparison of mandibular premolars and canines with respect to their resistance to vertical root fracture. J Dent 2004 May;32(4):265-268.

18. Kim HC, Lee MH, Yum J, Versluis A, Lee CJ, Kim BM. Potential relationship between design of nickel-titanium rotary instruments and vertical root fracture. J Endod 2010 Jul;36(7): 1195-1199.

19. Adorno CG, Yoshioka T, Jindan P, Kobayashi C, Suda H. The effect of endodontic procedures on apical crack initiation and propagation ex vivo. Int Endod J 2013 Aug;46(8):763-768.

20. Bürklein S, Tsotsis $P$, Schäfer E. Incidence of dentinal defects after root canal preparation: reciprocating versus rotary instrumentation. J Endod 2013 Apr;39(4):501-504.

21. Bürklein S, Hinschitza K, Dammaschke T, Schäfer E. Shaping ability and cleaning effectiveness of two single-file systems in severely curved root canals of extracted teeth: reciproc and WaveOne versus Mtwo and ProTaper. Int Endod J 2012 May;45(5):449-461.
22. Metzger $Z$. The self-adjusting file (SAF) system: an evidencebased update. J Conserv Dent 2014 Sep;17(5):401-419.

23. Pawar AM, Pawar MG, Kokate SR. Meant to make a difference, the clinical experience of minimally invasive endodontics with the self-adjusting file system in India. Indian J Dent Res 2014 Jul-Aug;25(4):509-512.

24. Yoldas O, Yilmaz S, Atakan G, Kuden C, Kasan Z. Dentinal microcrack formation during root canal preparations by different NiTi rotary instruments and the self-adjusting file. J Endod 2012 Feb;38(2):232-235.

25. Hin ES, Wu MK, Wesselink PR, Shemesh H. Effects of selfadjusting file, Mtwo, and ProTaper on the root canal wall. J Endod 2013 Feb;39(2):262-264.

26. Liu R, Hou BX, Wesselink PR, Wu MK, Shemesh H. The incidence of root microcracks caused by 3 different singlefile systems versus the ProTaper system. J Endod 2013 Aug;39(8):1054-1056.

27. Pawar AM, Pawar SM, Pawar MG, Kokate SR. Fracture resistance of teeth instrumented by the Self-Adjusting File, ProTaper NEXT and WaveOne. J Pierre Fauchard Acad 2014 Sep;28(3):83-87.

28. Kim HC, Sung SY, Ha JH, Solomonov M, Lee JM, Lee CJ, Kim BM. Stress generation during self-adjusting file movement: minimally invasive instrumentation. J Endod 2013 Dec;39(12):1572-1575.

29. Capar ID, Altunsoy M, Arslan H, Ertas H, Aydinbelge HA. Fracture strength of roots instrumented with self-adjusting file and the protaper rotary systems. J Endod 2014 Apr;40(4): 551-554.

30. Lee KW, Williams MC, Camps JJ, Pashley DH. Adhesion of endodontic sealers to dentin and gutta-percha. J Endod 2002 Oct;28(10):684-688.

31. Sousa-Neto MD, Marchesan MA, Pécora JD, Junior AB, SilvaSousa YT, Saquy PC. Effect of Er:YAG laser on adhesion of root canal sealers. J Endod 2002 Mar;28(3):185-187.

32. Mamootil K, Messer HH. Penetration of dentinal tubules by endodontic sealer cements in extracted teeth and in vivo. Int Endod J 2007 Nov;40(11):873-881.

33. Mandava J, Chang PC, Roopesh B, Faruddin MG, Anupreeta A, Uma Ch. Comparative evaluation of fracture resistance of root dentin to resin sealers and a MTA sealer: an in vitro study. J Conserv Dent 2014 Jan;17(1):53-56.

34. Chadha R, Taneja S, Kumar M, Sharma M. An in vitro comparative evaluation of fracture resistance of endodontically treated teeth obturated with different materials. Contemp Clin Dent 2010 Apr;1(2):70-72.

35. Chadha R, Taneja S, Kumar M, Sharma M. Influence of root embedment material and periodontal ligament simulation on fracture resistance tests. Braz Oral Res 2005 Jan-Mar;19(1): 11-16.

36. Alsamadani KH, Abdaziz el-SM, Gad el-S. Influence of different restorative techniques on the strength of endodontically treated weakened roots. Int J Dent 2012;2012:343712.

37. Saw LH, Messer HH. Root strains associated with different obturation techniques. J Endod 1995 Jun;21(6):314-320. 